\title{
Progress or development; word selection of progress in Islamic-Iranian model of progress
}

\author{
Mansur HeIDARI $^{1}$, Seyyed Mohammad Javad GHORBI ${ }^{* 2}$, Meisam BelbasI ${ }^{3}$ \\ ${ }^{1}$ Assistant Professor of Islamic teaching, Medical Science University, Hamedan, Iran \\ ${ }^{2}$ MA of political thought of Islam, Imam Khomeini research institute, Tehran, Iran \\ ${ }^{3}$ Ph.D. candidate of Islamic Revolution Studies, Tehran University, Tehran, Iran
}

\begin{abstract}
The design of Islamic-Iranian model of progress requires word selection of local words to achieve the real progress and this issue is observed in Islamic revolution process to use Islamic literature. These words are proposed as equivalents of common western terms. The word selection of progress in Islamic-Iranian process of progress indicates exact word selection for materialistic and spiritual progress. To do this, the present study is an analytic-descriptive design and library study to evaluate the importance of the term "progress" in the concept of IranianIslamic model of progress. The results show that the term development is conceptually ambiguous with western and liberal economic value and concepts not consistent with the Islamic and Iranian values and culture. The term progress has special requirements in accordance to the principles and components of Islamic-Iranian growth and all are aware of its meaning and can organize their relevant excellence road map.
\end{abstract}

Keywords: Progress, Development, Conceptual ambiguity, Islamic-Iranian model of progress.

\section{1- Introduction}

The structural features and cultural variety of undeveloped communities have caused that we cannot achieve a clear image of development of communities in the form of a theory or an approach. The value nature of studies has led into the biased judgment of the realities of development [1]. Although development is one of the important issues in practical and theoretical fields, after the Second World War, the term development had new dimensions in national and international policies. Development and the relevant issues have been applied in academic conferences and they have received much attention in some curriculums. Development is of great importance in social and political theories and many theorists have focused on development and fundamental thought schools have been founded [2]. After the Second World

\footnotetext{
* Corresponding Author
} 
War, economic development had received much attention in economic theories. This issue concentrates on a special topic and it is an independent field of economics. Also, different approaches of development have been emerged in the relevant literature. The considerable progress in development issue is not only selection of practical strategies or recommendations to achieve developed and it includes even the concept of development and with the growth of development theories and its application, relevant revisions and failures have been changed considerably in theory and practice [3]. The present study is an analytical-descriptive design to evaluate the significance of the term progress in the concept of Iranian-Islamic model of progress.

\section{2- The ambiguities of the concept of development}

Development is with considerable changes in the advanced communities and it includes a wide theoretical and conceptual change trend [4]. Development is prevalent in the public culture of people around the world and the majority of people attempts to achieve it as the ideals of most of present communities is achieve the condition of developed communities [5].

According to Tony Edison, the response to development questions is interesting as they are changed over time in different places and most of development issues have been challenging [6]. This requires the theoretical challenges as the majority of discussions are turned into ideological issues or the conflict between scientific theories of "We" and ideological theories of "Others" [7]. Some of the development theorists including "George Lav" believe that "Development dominance era" [8] is passed but other researchers believe that development literature shows that in development discourse, the west dominance is hidden [9] and westernized approaches to development have eliminated the conceptual and empirical correlation of development [10].

These theorists believe that the western development has destroyed the civilizations and by new technologies, "technological subsistence" is used as an alternative for spiritual requirements of people [11].

Development is a value-based concept including all actions to fulfill a regular set of collective and individual conditions as determined suitable in association with some values [12]. The value and norm based nature of development includes a wide range of differences of beliefs and values of people and societies [13]. The ambiguity of development concept is summarized as: The part approach to development issue, application of development among people without considering its true meaning, common use of the term development in political, economic and cultural literature, special meaning value, political nature, western nature of this term and having consistent cultural and political requirements with western culture, general basis of the term development, materialistic approaches to development have been effective on the ambiguity and similar perception of development. 
Bulletin de la Société Royale des Sciences de Liège, Vol. 86, special edition, 2017, p 406 - 420

\section{3- The concept of development 3-1 Literal meaning}

The term development is derived of develop as the act or process of growing or causing something to grow [14]. Literally, development means growing, expanding, maturing, evolution, enlargement, etc.[15].

Development attitude means developing as common in lexicology and refers to the quantitative and expansive growth [16] but we shouldn't consider development as materialistic and quantitative (economic) and this term refers to a qualitative process. For example, in Islamic discourse, we consider the human and society excellence, great ethical and spiritual characteristics [17]. If we consider development as quantitative, the goal of development is considered as its materialistic achievements, the minimum living condition and this is a limited interpretation of development. In literal definition of development, we should consider what is important in human salvation and it has a wide concept [18]. According to Michele Todaro, development should be considered as a multi-dimensional aspect requiring the change of organization and the relevant orientation of socio-economic system of the country and besides enhancement of income and production, development includes fundamental changes in institutional, social and administrative structures [19].

Developed is derived of the word "Vasa" in Arabic meaning expansion. This term means spiritual and materialistic development. Regarding materialistic development, it is written in the

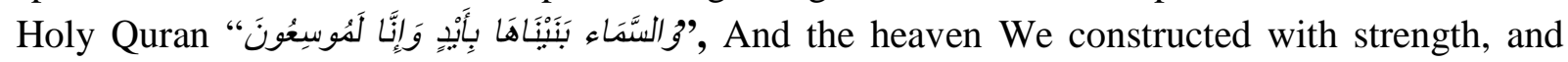
indeed, We are [its] expander [20]. According to Nahjolbalaghe, "هو الذى وسع سععه الصوات" By Allah, as the voices ranges are heard by Him. The spiritual development is also mentioned in the

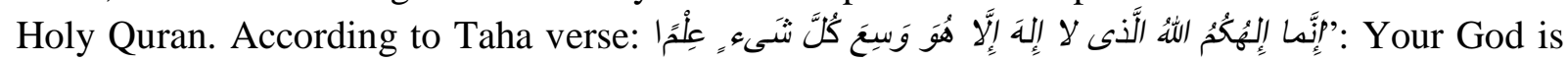
only Allah, except for whom there is no deity. He has encompassed all things in knowledge [21]. According to the Holy Quran, development means conscious development. Development is not only production process and it is human process with the aim of one's development in materialistic and spiritual fields [22].

\section{3-2 Conceptual interpretation}

The majority of people state something by development expression as inconsistent with their intention and this is ambiguous [23]. Development is the desired concept of all people and human communities and according to "Gerald Meier", "What is not development" shows that development is extensive as a comprehensive definition and development dimensions as economic, political or cultural development are with difficulties [24]. We should consider that any form of definition of development is a value concept with normative assumptions. Park considers development as a purposeful process as raised as a movement to good conditions of human life structure [25]. Development is a process in which the society is changed from an 
unsuitable condition to a suitable condition and the society talents are actualized from economic, social, cultural and political aspects [26]. If the society can not take a step to these political, economic and cultural desires, it is a passive and statistic society. According to Ali Shariati, "A static society with close world view, culture, economy and politics resists against any innovation. In other words, it is tradition-based to maintain the existing condition. A dynamic society is the one with open world view, culture, economy and politics. Despite the static society, this society is future based and new elements are observed in it, it is evolving continuously [27].

In the early years after the Second World War, the term development was applied equal to growth. The theories of some western researchers including "Rostow" are based on such definition of development. Rostow considers development as a multi-stage process passing traditional, transition, development and maturity and reaches the highest level of economic growth as mass consumption. Rostow distinguishes each stage of the above stages of economic criteria as investment, fair growth, consumption, etc. This definition is accepted by UN ignoring some issues as poverty, unemployment and other social and economic disorders. It was shown that considering development equal to economic growth is not true. Thus, some features as reduction of poverty and inequality are included in the concept of development and development as "social life enhancement" is considered. Dadli Siers believes that for development in a country, we should see whether beside the increase of per capita revenue, poverty, unemployment and inequality are changed or not? He believes that if these indices are improved, we can say development is occurred. These definitions show social-idealistic approach of development and don't refer to the mechanisms and tools to achieve goals or coping with the barriers of development [28]. Here, we refer to some of the definitions of theorists.

Gunnar Myrdal believes that development means continuous improvement of the total society and social system to a better life. A better life means modernization ideals. Myrdal expresses some of these ideals as useful value premises as a measure to evaluate development including: Rationality, development and planning for development, rise of productivity, rise of levels of living, social and economic equalization, improved institutions and attitudes, national consolidation, national independence, political democracy in a narrow sense and social discipline. Michele Todaro believes that development is a multi-dimensional process requiring basic changes in social structure, attitude of the public and national institutes and enhanced economic growth, reduced inequality and poverty eradication [29].

Black believes that development means achieving some of "modernization ideals" including the productivity increase, social and economic equality, modern knowledge, improvement of attitudes and advanced institutes and establishment of a rational system for policy making and can eliminate some of the unsuitable conditions in undeveloped social systems [30]. In political science dictionary, development is defined: Improvement, growth and enhancement of all 
materialistic and spiritual conditions, increasing the capacity of social system, meeting the demands of a society and enhancing the life quality of people in society [31].

Ali Shariati states: Progress is determining an assumed goal and the attempt to proceed a person to the ultimate goal as determined already. Thus, progress is based on being pessimist to the present condition and the faith in a clear future [32]. According to Seyyed Hossein Nasr, development is closely associated with Utopianism and should be evaluated in terms of Islamic ideas and values [33]. He states "The ideal of continuous progress is based on a Utopianism being inspired of an abolished traditional basis [34]. According to Mohammad Hossein Beheshti, "Human being consists of two aspects, materialistic and physical referring to body and another aspect is spiritual referring to soul. Human being should be developed based on these two aspects [35].

According to Mohammad Bagher Sadr, progress is evolution and changes occurred in a society" with two major aspects: First, moving toward a better life, development and optimization, second, moving toward purity and excellence of attitudes [36]. Islamic development is the process of long-term, comprehensive, structural and qualitative changes inside an Islamic, cultural-social system called society meeting the real demands of the people using a rational method in accordance to Islamic goals and rules. In this process, the social, economic, political and cultural sub-systems of the mentioned society are enhanced accordingly and by relative autonomy from each other can generate wealth, power, cohesion and knowledge [37].

\section{4- The common concepts of development}

A concept of development is required to include socio-economic goals. However, according to Anthony Thirlwall this is a difficult task [38]. The difficulty is due to the fact that the concept of development is used in different meanings in humanity, social science and policy making [39]. Adrian Leftwich refers to eight common concepts of development and the most important examples: The historical progress, using natural resources, planned social, political and economic progress, condition, process, structural change, modernization and the increase of production forces [40]. Some of them are elaborated as:

\section{4-1 Development as historical progress}

According to Morteza Avini, development is a new concept in our present culture but it is not a new meaning. This meaning is one of the first achievements of westernization in our country. The term "progress" is one of the first words applied by those taking a trip to the abroad. To perceive the meaning of development, we should perceive the concept of progress as progress is an unavoidable for human being and the basis of the present civilization is in his materialistic 
and spiritual dimensions [41]. Thus, progress is a stepwise and forward movement, an active movement not a movement affected by another force [42]. Adrian Leftwich believes that the term development is closely associated with the term progress and this association has a historical ground in different societies. According to Cowen and Shenton, like capitalism, development has an evolutionary process. This progress idea is used as a continuous, reliable, progressive process based on using energy and rationality of human being to perceive the systematic change of the world. In this thought (historical progress), changes of development are the processes of human actions. There are different interpretations of these processes including the use of scientific and rational processes, liberalization of commercial abilities of people from the state limitations, technical processes and economic planning. Such interpretations are based on the improvement of living style, scientific knowledge, individual freedom, equality and autonomy [43].

\section{4-2 Development as economic growth}

Most economists rely on the term "growth" in the analysis of economic changes [44] focusing on quantitative changes. In economic issue, growth requires changes in some economic aspects including different dimensions of economic development. If production is increased in a definite period, we consider that growth is occurred but the concept of development refers to another phenomenon beside the increase of production and it is a qualitative concept [45].

Development as economic growth is raised as the first clear meaning by economists since the second half of $20^{\text {th }}$ century. By a quantitative evaluation about the condition of western countries, they applied "Per capita income growth" and expressed the growth of communities. The initial designers of development reduced it to economic growth and this had negative effect on this concept, but judgment about communities is as achievable. Some theorists as Rostow applied per capita income growth to define the development mechanism [46]. Rostow believes that per capita income growth requires definite value of saving, investment and foreign aids. He believes that to achieve the highest level of economic growth, mass consumption, the communities should take traditional, preconditions for take-off, take-off, drive to maturity and age of high mass consumption [47].

Economic growth refers to the continuous annual increase of GDP or per capita income. It is true that there are a few countries with such condition [48]. We can say economic growth is the increase of economic data as computed in the form of GDP [49]. Besides capital collection, this view as the most important economic growth factor focuses on other production factors as human resources, natural resources, etc. and is not restricted only to national income and national production [50]. 
Bulletin de la Société Royale des Sciences de Liège, Vol. 86, special edition, 2017, p 406 - 420

\section{4-3 Development as evolution}

Fairchild considers evolution as a changing process in which each new stage includes the previous stage features besides the special features. In other words, evolution is the continuous growth or development. Halt considers evolution as regular change or growth process in which each new stage is an extended development but it doesn't negate the previous stage. By Darvin theories, Spencer raised evolutionary theory and social evolution. Spencer believes in unilinear evolution and believes that all societies take an evolutionary line [51].

According to the western economists, evolution refers to cultural progress but it emphasizes on the materialistic dimensions of growth and evolution. In Islamic approach, evolution includes both materialistic and spiritual progress. According to Avini, the concept of evolution in the Holy Quran refers to the spiritual dimensions of human being but the spiritual evolution is not consistent with the materialistic development of human being and it mostly refers to contentment, balance, avoiding enjoyment (its Quranic meaning) and excellence is found in selfsacrifice, coping up with desires and lust. For human evolution and growth, an Islamic government should consider the spiritual aspects of human being and eliminate the barriers to the spiritual excellences and one of the barriers is poverty. Thus, first, poverty eradication is not a main issue and the aim should be achieving social justice not development. Thus, education and culture are not used to eradicate poverty and this aim is achieved by spiritual and cultural enhancement [52].

\section{4-4 Development as modernization}

"Modernization" is equal to modernization, re-build and after the Second World War during 1950, 1960, it was raised as a dominant approach in social science literature [53].

Modernization refers to a process in which strategic functional roles of a society are active in construction and production. Some scientists associate modernization to specialized political structures and political power among all sectors and relevant society fields. Thus, stability, balance and coordination are emphasized in society [54]. In modernization idea, it is assumed that human community processes are developed from the simple traditional forms to modern complex structures [55]. Other assumptions of this idea include: A process is stepwise, homogenous and convergent; other countries should imitate them, there is a progressive and long-term process [56].

Eisenstadt believes that historically, modernization is the process of changing to the social, economic and political systems as developed in Western Europe and Northern America during $17^{\text {th }}$ century to $19^{\text {th }}$ century and then in the $19^{\text {th }}$ century, developed in other European countries 
and in the $20^{\text {th }}$ century in Latin America, Asia and America." Wilberth More" considers modernization as the complete change of traditional community and Zivand considers it as a modern world. "Sireil Black" considers modernization as a historical process in which the institutes accept various functions for the increase of human knowledge and control of nature forces with revolution. According to Robert Ward, the features of new society include: High capability to affect the natural and social condition of environment and based on the value system as optimistic to the suitability of this capability [57].

Modernization theory is the result of combination of social evolution of Herbert Spencer, functionalism of Talcott Parsons and rationality of Max Weber [58]. We can say modernization is beyond the economic growth and according to "Ingham", modernization is a comprehensive process including various dimensions [59]. We can say this view considers complexity and creating various political, cultural, socio-economic structures equal to development. In the majority of modernization theories, west is a role model and other developing communities should take a model of west as the development pioneer and local conditions, cultural and political requirements of other communities are ignored in this regard.

This paper has a comprehensive view to development. The progress considered by the author has materialistic and spiritual dimensions and is not restricted only to materialistic and economic components and it includes stable growth, materialistic and spiritual excellence.

\section{5- A word, progress or development}

Most of researchers focus on this question that why the term progress is used instead of development? The need to a common language is unavoidable for scientific exchange; this doesn't mean the lack of changing scientific concepts. The role of concept and conceptualization in scientific theories is important.

The claim of worthless scientific concepts is a challenging issue. Regarding humanity and social concepts, namely the concepts with descriptive or value-based meaning, this is discussed mostly. Description of a society to mountainous, arid, Mediterranean climate, earthquake-stricken is different from dividing a society into developed and undeveloped. This difference is based on value leading to development. Simon Kuznets believes that political and social values are combined with the development as secularism, nationalism and equality. Gunnar Myrdal explains the implicit value basics in a developed community and refers to some of the values hidden in development ideals as rationality, improvement and improved life style, social, economic equality and democracy. These values are raised in different cultures and communities but their experience in western civilization, their definitions of experience, non-important nature of some of social values as autonomy, spirituality, ethics, etc. are parts of value beliefs with the development concept [60]. The lack of correct perception of economic approaches is important if 
a person is encountered with economic features in social life and culture-based rational behavior and national values can be manifested. In this regard, no organized knowledge of concepts, or a framework of analysis and economic culture follow an individual in the society. Thus, this has a negative impact on economic growth. This person acts as a family member, labor, citizen in social field, consumer, producer of goods, investor in different collective and individual aspects as norms of work, consumption, taking optimized decisions, costs-benefit culture, efficient use of resources, interaction with human and physical environment including environment, etc. The collective behaviors in such space can lead to the growth or collapse of a nation [61].

Thus, Imam Khomeini refers to the correct selection of words and believes that most of words are not consistent with their implicit meaning [62] and present "localization and selection of local words" strategy [63]. In the definition of Islamic Iranian model of progress we should select the words to consider some items as ethical and spiritual virtue of human being, justice, culture, identity and local science [64]. The term progress is a localized concept of development considering the above components. We should consider that this term is considered for respecting the values in national and religious achievements of Iran [65]. The Islamic-Iranian model of progress focuses on local progress. We should attempt to be careful in selection of suitable words. The selection of the term progress instead of development concept is due to the clarity of progress nature for Iranian community and it includes local requirements of Iranians with suitable norms in accordance to Islamic-Iranian culture [66]. This local model applies the term progress as the term development has special meaning and value and it has its special cultural and political requirements [67]. Thus, the concept of progress is different from its western concept. If we refer to progress, we don't mean the common western concept. In our lexical system, the term progress has its special meaning and it is not equal with the development in western lexical system. Our goal is not western development with the same indices [68]. The selection of the term progress instead of development is an intentional issue as we can separate the development requirements from the local model of progress. According to the leader of Islamic Revolution: "We don't want to use a common global term with its special meaning in our country. We present our own concept. This concept is "progress". We perceive the goal of progress" [69]. If we use progress instead of development, a new thought is replaced with the common interpretations of development in accordance with local conditions and cultural and social requirements. Some of these descriptions are as follows:

\section{6- New thought attitude of progress in alternative models}

The term "progress" is selected instead of "Development" with some thought concepts explained in Islamic-Iranian model. These new thought forms include:

a. Economics as an instrument for human development: Economic growth doesn't make development automatically. Economic growth is interrelated as a set of defined human, 
cultural and social goals. We should view economic growth as human development tool to meet the basic needs of people and to improve their life quality. In Islamic-Iranian model of progress, human development includes materialistic and spiritual dimensions and there is a logical association between these two dimensions.

b. The progress purpose based on people: Economic growth is not only defined by the increase of GDP and per capita income. Both of them are necessary but without purposeful orientation, the progress goals are failed. A major share of benefits of growth is dedicated to high income social class and the masses are ignored in bad conditions. We should focus on people, society and fair distribution of goods and services. The experience has shown that this increases growth. Thus, investment shouldn't lead only to the improvement of individual condition and it should enhance the society to cope up with effective methods.

c. Justice-based structural changes: The basic change of structure is necessary to achieve progress model goals. This necessity is replicated many times but in the majority of developing countries, the attempt for structural change is weak. The direction of personality system change and social system are explained carefully but it is not clear how the communities should be provided to achieve these changes. The economic opportunities should be open and injustice should be eliminated. This is not possible without the major reforms of production, conscious discrimination policy and masses information [70].

d. Local democracy, the efforts of the past decade development have been misleading considerable. Some privileges have been given to history and tradition, but local creativity has always been controlled. A small elite group (with western orientation) has taken major present and future decisions and people have not crucial role in the decisions. In the countries in which democracy is established, people selection is restricted to a political party or another political party under the leadership of elites and their attitude is different only in minor principles. To guaranty local growth, a new institutional framework and giving important roles to people, societies can be necessary.

e. Maximum participation of people in progress, we should take some steps for participation of development process and this is achieved when people have real access to power and resources. The democracy that is achieved only by periodical elections is not participation. We shouldn't eliminate the innovation of people and the mass collection of people shouldn't only be considered based on the acceptance of the mass regarding the decisions taken in elite dominant centers. In other words, people not only take decsions about their present and future, they should have crucial role in implementation of development and growth plans. 
f. Foundation of stable progress as conscious, the important element that is ignored in development planning is its stability. The majority of developing countries consciously and unconsciously attempt to imitate the west without any awareness of their resources and restrictions. Indeed, the rich countries have achieved the condition in which their development is unstable. Inflation, stagnation, unemployment, environmental risks, etc. are true examples. Developing countries should stabilize their progress consciously. The scientific and technological progresses play important role in the stable progress [70]. The Islamic-Iranian model of progress is based on the fact that the progress planning should be stable and this is achieved by wise approaches.

\section{7- Conclusion}

The discourse of Islamic revolution of Iran attempts to eliminate deprivation and by ignoring liberalistic and socialistic development presents an alternative model for progress. Progress is the required condition for the prosperity of society in materialistic and spiritual fields focusing on new development to fulfill equality and justice in society. The design of Iranian-Islamic model of progress requires the selection of local words to achieve real progress. The term development is conceptually ambiguous with western and liberal economic value and concepts not consistent with the Islamic and Iranian values and culture. The selection of the term progress in Islamic Iranian model of progress indicates exact word selection for materialistic and spiritual progress. Fifth, progress has special requirements in accordance to the growth principles and policies and Islamic-Iranian excellence and all are aware of its general meanings and can organize their roadmap based on it. Progress opposite to the thought frames of development has some thought concepts and they can be evaluated in Islamic-Iranian model. These new thought forms include economic growth as an instrument for human development, people-based progress purpose, the justice-based structural changes, local democracy, maximum participation of people in progress process.

\section{References}

[1] Ghavam, Abdolali, 2005. The challenges of political development. Tehran. Ghomes. P. 29.

[2] Sai, Ahmad. 2007. Development in contradictory schools. Tehran. Ghomes, P. 1.

[3] Arabi, Seyed Hadi, et al., 2004. Development based on changes. Qom. University and religious institute. P. 18-19.

[4] Movaseghi, Seyed Ahmad. 2004. Development, conceptual and theoretical changes. The journal of faculty of law and political science. NO. 63, p. 223.

[5] Jahanian, Naser. 1998. The change of development concept and its relationship with religion. Ghebsat, No. 7. P. 109. Larijani, Mohammad Javad. 1998. Religion, government and development. Tehran. Contemporary thought. P. 11. 
[6] Edison, Tony. 2008. Development in the third world issues. Translated by Sai and Mirtorabi. Tehran. Ghomes. P. 240.

[7] Su, Alvin. 2009. The social change and development. Translated by Mahmoud Habibi Mazaheri. Tehran. Strategic studies research center. P. 19.

[8] Badie, Bartaran. 2008. Political development. Translated by Ahmad Naghibzade, Tehran. Ghomes. P. 15.

[9] Ghafari, Yashil. 2011. The changes of development theory in globalization and identity of nations. Strategic studies of globalization. Year 2. No. 2. P. 111.

[10] Azadarmaki, Taqi. 2007. Development sociology: Principles and theories. Tehran. Elm. P. 1.

[11] Avini, Seyed Morteza. 2013.b. Against global unified culture. World. The green book electronic edition. P. 3-4.

[12] Dirbaz, Asgar, Dadgar, Hassan. 2007. A review of Islam and sustainable development. Tehran. Javan. P.15.

[13] Divsalar, Abdolrasul. 2012. Review of the concepts of progress and development with emphasis on western thought. Islamic-Iranian model of progress. First Vol. Tehran. Justice message. P.219.

[14] Bakhtiari, Sadegh. 2006. Justice and development from the view of Imam Ali. Religious center thought. Year 7. NO. 2. P. 100, Aghajani, Nasrollah. 2000. Islam and development. Knowledge. Year 9. NO. 7. P. 99. Ameli, Ahmad. 2001. Justice and development from the view of leadership. Thought. Year 7. NO. 2. P. 5-6.

[15] Baradaran Haghir, Maryam. 2011. The educational components of human development. Tehran. Imam Sadegh. P. 22-23.

[16] Alayi, Hossein. 2011. The effective components on formulation of Islamic-Iranian model of progress. Defense policy. Year 19. No. 74, p. 15.

[17] Baghi, Abdolreza. 2011. A review of meaning and western development and IslamicIranian development. Political and international researches. Year 3. No. 7. P. 127.

[18] Asghari, Mahmoud. 1998. A review of development and its achievement. Religious center thought. Year 4. NO. 3. P. 125.

[19] Todaro, Michele. 1988. Economic development in the third world. First Vol. Translated by Farjadi, Tehran. Plan and budget organization. P. 115.

[20] Holy Quran, Zariat/47.

[21] Holy Quran/Taha/98

[22] Akhtarshahr, Ali. 2007. Islam and development. Tehran: Islamic thought and culture institute. P. 21-22.

[23] Esteva, Gustav. 1998. Development in a new view to development concepts. Translated by Farahi and Bozorgi, Tehran. Markaz. P.13.

[24] Sobhani, Hassan. 2006. Justice in religion and development. Religious center thought. Year 7. No. 2, p. 28. 
Bulletin de la Société Royale des Sciences de Liège, Vol. 86, special edition, 2017, p 406 - 420

[25] Abasi, Ebrahim. 2004. Pahlavi government and economic development. Tehran. Islamic revolution document center. P. 25-26.

[26] Nabavi, Seyed Morteza. 2011. Development dimensions in Iran: Yesterday and today. Thirty year result of Islamic Republic of Iran. Vol. 3. Tehran. Tehran University. P.14.

[27] Rad, Firooz; Jahaninasab, Nahid. 2002. Sociology of cultural development. Tehran: Chapakhsh. P.129.

[28] Saei, Ahmad. 2008. Economic-political issues of the third world. Tehran. SAMT. P.1819.

[29] Ghorbi, Seyed Mohammad Javad. 2013. The ethical reading of security in local progress model. In progress concepts and basics. Vol. 2. Tehran. Islamic-Iranian model of progress. P. 1093-1094.

[30] Jahanian, Naser. 2008. Progress and duties of religious government. Political knowledge. Year 1. No. 1. Jp. 68.

[31] Farahnai, Mohammad. 2004. The analysis of development in Iran. Tehran. Porsman. P.15.

[32] Shariati, Ali. 1980. Civilization history. Vol. 2. Tehran. The office of the works of Dr. Shariati. P.220.

[33] Nasr, Seyed Hossein. 2011. Utopia. Mehr verse. No. 52-53. Mehr Aban 2011. P. 159.

[34] Nasr, Seyed Hosein. 2011. Utopia. Mehr verse. No. 52-53. Mehr Aban 2011. P. 159160

[35] Hosseinibeheshti, Seyed Mohammad et al., 2011. Islam recognition. Tehran. Rozane. P.264.

[36] Jamshidi, Mohammad Hossein. 1998. Political thought of Shahid Rabe. Tehran. Ministry of foreign affairs. P.123.

[37] Jahanian, Naser. 2009. Progress and the duties of religious government. Political knowledge. First year. NO. 1. P. 68-69.

[38] Tirlwal, Antony p. 1999. Growth and development. Translated by Farhang and Hosseini. Tehrna. Islamic guidance ministry. P. 38.

[39] Azadarmaki, Taqi. 2007. Development sociology. Principles and theories. Tehran. Elm. P.2.

[40] Leftwik, Adrian. 2005. Politics and development in the third world. Tehran. Abrar Moaser. P.39.

[41] Avini, Seyed MOrteza. 2013. In the meaning of development. Western development and civilization. Green book. P.3.

[42] Mark henry, Paul. 1995. Poverty, progress and development. Translated by Mohammadi. Tehran. Political and international studies. P.61.

[43] Leftwik, Adryan. Politics and development in the third world. Tehran. Abrar Moaser. P.39-40.

[44] Arthur Lewis, William (1956), the Theory Of Economic Growth, London: Allen and Unwin, p 225. 
Bulletin de la Société Royale des Sciences de Liège, Vol. 86, special edition, 2017, p 406 - 420

[45] Baradaranhaghir, Maryam. 2011. Educational components of human development. Tehran. Imam Sadegh. P.27-28.

[46] Azadarmaki, Taghi. 2007. Development sociology. Tehran. Elm. P.4.

[47] Afrugh, Emad. 2000. A theoretical view to development analysis. Tehran. Culture and knowledge institute. P.82.

[48] Leftwik, Adryan. 2005. Politics and development in the third world. Translated by Khosravi and Mirahmadi, Tehran. Abrar Moaser. P.49.

[49] Hajiyusefi, Amirmohammad. 1999. Government, oil and economic development in Iran, Tehran. Islamic revolution documents center. P. 49.

[50] Farjadi, Gholamali. 1991. Economic development in the third world. Tehran: Planning and budget organization. P. 133.

[51] Lahsayizade, Abdolali. 2011. Development sociology. Tehran. Payam-e Noor University. P. 2.

[52] Avini, Seyed Morteza. 2013. In development meaning. In western civilization and development. Green book publication. P.6-8. Avini, Seyed Morteza. 2013 a. Evolution or progress. In western civilization and development. Green book. P. 187-195.

[53] Azkia, Mostafa. 2001. Development sociology. Tehran. Kalame. P.87.

[54] Ghavam, Abdolali. 2005. The challenges of political development. Tehran. Ghomes. P.86.

[55] Leftwik, Adryan. 2005. Politics and development in the third world. Translated by Khosravi and Mirahmadi. Tehran. Abrar Moaser. P.56.

[56] Su, Alvin. 2009. The social change and development. Translated by Mazaheri, Tehran. Strategic studies. P.23-67.

[57] Sai, Ahmad. 2007. Development in contradictory schools. Tehran. Ghomes. P.59-60.

[58] Amjad, Mohammad. 2005. The comparative evaluation of economic development in Iran and South Korea. Tehran. Islamic revolution documents center. P. 56-57.

[59] Abbasi, Ebrahim. 2004. Pahlavi government and economic development. Tehran. Islamic revolution documents center. P. 23-24.

[60] Arabi, Seyed Hadi. 2012. The position of Islamic values in formulation of IslamicIranian model of progress. In Islamic-Iranian progress model. First Vol. Tehran. Justice message. P. 271-273.

[61] Toghyani, Mehdi, Zahedivafa, Mohammad Hadi. 2012. Using Islamic civilization works in the design and formulation of Islamic-Iranian model of economic culture. Islamic economy knowledge. Year 3. No. 6. P. 57-58.

[62] Khomeini, Seyed Rohollah. 2006. Sahife Emam. Vol. 4. Tehran. Imam Khomeini institute. P. 270.

[63] Khomeini, Seyed Rohollah. 1989. The divine political will. Tehran: Ministry of Islamic guidance and culture. P.37. 
Bulletin de la Société Royale des Sciences de Liège, Vol. 86, special edition, 2017, p 406 - 420

[64] Nekonam, Ali. 2011. The requirements of Islamic model of growth and progress in justice in Islamic-Iranian model of progress. Hamshahri. New period. No. 78. P. 198203.

[65] Hosseinzade, Hassan. 2011. The relationship between justice and progress in justice in Islamic-Iranian model of progress. Hamshahri, New period. No. 78. P. 264.

[66] Siahposh, Amir. 2011. Islamic-Iranian model of progress. Tehran. Aftab Tose. P. 103104.

[67] Secretariat of strategic thoughts conference. 2011. The statements of Islamic revolution leader in the first conference of strategic thoughts. In Islamic-Iranian model of progress. Tehran. Justice message. P. 9-10.

[68] Khamenei, Seyed Ali. 2009. The statements in visit to the teachers and students of Kordestan province.

[69] Khamenei, Seyed Ali. 2010. The statements of our leader in the first conference of strategic thoughts.

[70] Seif, Allahmorad. 2010. The concept study of local model of development of Islamic Republic of Iran. Basij studies. Year 13. NO. 48. P. 31-32. 